УДК 661.832.2:544.723

\title{
СТРУКТУРА И СОРБЦИОННЫЕ СВОЙСТВА ПОРИСТЫХ УГЛЕРОДНЫХ СОРБЕНТОВ ИЗ КОРЫ ОСИНЫ*
}

\author{
() Е.В. Веприкова ${ }^{1 * *}$, И.П. Иванов ${ }^{1}$, Н.В. Чесноков ${ }^{1}$, Б.Н. Кузнецов \\ ${ }^{1}$ Институт химии и химической технологии СО РАН, Федеральный \\ исследовательский центр Красноярского научного центра СО РАН, \\ Академгородок, 50/24, Красноярск 660036 (Россия), e-mail: veprikova2@mail.ru \\ ${ }^{2}$ Сибирский федеральный университет, пр. Свободный, 79, Красноярск, 660041 \\ (Россия)
}

\footnotetext{
* Полный текст статьи опубликован: Веприкова Е.В., Иванов И.П., Чесноков Н.В., Кузнецов Б.Н. Структура и сорбционные свойства пористых углеродных сорбентов из коры осины // Химия растительного сырья. 2019. №3. C. 325-333. DOI: 10.14258/jcprm.2019035180

${ }^{* *}$ Автор, с которым следует вести переписку.
} 


\section{Статистический анализ результатов определения сорбции метиленового синего и витамина В12 сорбентами из коры осины.}

Статистический анализ для величин сорбции метиленового синего (МС) и витамина $\mathrm{B}_{12}$ проведен на основе данных, приведенных в таблице.

Параметры пористой структуры и сорбционные свойства углеродных сорбентов из коры осины (СКО)

\begin{tabular}{|c|c|c|c|c|c|c|}
\hline \multirow[b]{2}{*}{ Сорбент } & \multirow{2}{*}{$\begin{array}{c}\text { Температура } \\
\text { получения } \\
\text { карбонизата, }{ }^{\circ} \mathrm{C}\end{array}$} & \multirow[b]{2}{*}{$\mathrm{S}_{\mathrm{BET}}, \mathrm{M}^{2} / \Gamma$} & \multirow[b]{2}{*}{$\mathrm{V}_{\mathrm{mi}}, \mathrm{cm}^{3} / \Gamma$} & \multirow[b]{2}{*}{$\mathrm{V}_{\mathrm{me}}, \mathrm{cm}^{3} / \Gamma$} & \multicolumn{2}{|c|}{ Сорбция, $\mathrm{A}^{\text {мах }}$, мг/Г } \\
\hline & & & & & $\mathrm{MC}$ & Витамин $\mathrm{B}_{12}$ \\
\hline СКО-1 & 300 & 1448 & 0.46 & 0.16 & $395.9 \pm 8.5$ & $55,4 \pm 1,4$ \\
\hline СКО-2 & 400 & 1788 & 0.56 & 0.17 & $422.6 \pm 9.1$ & $45,8 \pm 1,1$ \\
\hline СКО-3 & 500 & 1882 & 0.58 & 0.18 & $457.3 \pm 9.4$ & $44,3 \pm 0,9$ \\
\hline СКО-4 & 600 & 1476 & 0.46 & 0.09 & $369.6 \pm 8.4$ & $37,7 \pm 0,7$ \\
\hline СКО-5 & 700 & 1386 & 0.41 & 0.08 & $349.1 \pm 8.2$ & $36,6 \pm 0,7$ \\
\hline СКО-6 & 800 & 1266 & 0.42 & 0.08 & $332.1 \pm 7.7$ & $35,8 \pm 0, /$ \\
\hline & A-H* & 638 & 0,24 & 0.06 & $256.9 \pm 7.7$ & $61.4 \pm 1.4$ \\
\hline
\end{tabular}

Примечание. $V_{m i}, V_{\text {те }}$ объемь микро и мезопор, $A^{\text {мах }}$-максимальная сорбция маркеров,

УА-Н *-образеи сравнения.

Число повторения опыта во всех случаях определения средних значений величин сорбции равно 3.

1. Вопрос о статистической значимости различий величин сорбции образцов сорбентов из коры осины, полученных при различной температуре.

1.1. Сорбция метиленового синего

Число степеней свободы 12, ошибка воспроизводимости (усредненная) 7.53 мг/г, ошибка определения среднего -4.35 мг/г.

Введем обозначение образцов:

CKO-1 CKO-2 CKO-3 CKO-4 CKO- 5 CKO-6
(0)
(1)
(2)
(3)
(4)
(5)

В соответствии с правилами применения критерия Дункана расположим результаты в порядке возрастания:

CKO-6 CKO-5 CKO-4 CKO-1 CKO-2 CKO-3
(5)
(4)
(3)
(0)
(1)
(2)

Выпишем значимые ранги рангового критерия Дункана при уровне значимости 0.05 и степени свободы 12 :

$\begin{array}{llllll}\mathrm{p} & 2 & 3 & 4 & 5 & 6\end{array}$

Ранги $3.08 \quad 3.23 \quad 3.33 \quad 3.36 \quad 3.40$

Наименее значимые ранги (НЗР), умноженные на ошибку среднего, равны:

$\begin{array}{lccccc}\mathrm{p} & 2 & 3 & 4 & 5 & 6 \\ \text { HЗP } & 13.39 & 14.05 & 14.49 & 14.62 & 14.79\end{array}$

$(2)-(5)=125.1>14.79 ;(2)-(4)=108.2>14.62 ;(2)-(3)=87.7>14.49 ;(2)-(0)=61.4>14.05$;

(2) $-(1)=34.7>13.39$.

$(1)-(5)=90.5>14.62 ;(1)-(4)=73.5>14.49 ;(1)-(3)=53>14.05 ;(1)-(0)=26.7>13.39$.

$(0)-(5)=63.8>14.49 ;(0)-(4)=46.8>14.05 ;(0)-(3)=26.3>13.39$.

(3) $-(5)=37.5>14.05 ;(3)-(4)=20.5>13.39$.

(4) $-(5)=17>13.39$.

Таким образом, различия величин сорбции МС для всех сорбентов из коры осины статистически значимы.

\section{2. Сорбичия витамина $B_{12}$}

Число степеней свободы - 12, ошибка воспроизводимости (усредненная) -0.77 мг/г, ошибка определения среднего -0.45 мг/г.

В соответствии с правилами применения критерия Дункана расположим результаты в порядке возрастания: 
СКО-6 СКО-5 СКО-4 СКО-3 СКО-2 СКО-1
(5)
(4)
(3)
(2)
(1)
(0)

Выпишем значимые ранги рангового критерия Дункана при уровне значимости 0,05 и степени свободы 12 :

$\begin{array}{llllll}\mathrm{p} & 2 & 3 & 4 & 5 & 6\end{array}$

Ранги $3.08 \quad 3.23 \quad 3.33 \quad 3.36 \quad 3.40$

Наименее значимые ранги (НЗР), умноженные на ошибку среднего, равны:

$\begin{array}{lccccc}\mathrm{p} & 2 & 3 & 4 & 5 & 6 \\ \mathrm{H} 3 \mathrm{P} & 1.39 & 1.45 & 1.50 & 1.51 & 1.53\end{array}$

$(0)-(5)=19.6>1.53 ;(0)-(4)=18.8>1.51 ;(0)-(3)=17.7>1.50 ;(0)-(2)=11.1>1.45 ;(0)-(1)=9.6>1.39$.

$(1)-(5)=10>1.51 ;(1)-(4)=9.2>1.50 ;(1)-(3)=8.1>1.45 ;(1)-(2)=1.5>1.39$.

$(2)-(5)=8.5>1.50 ;(2)-(4)=7.7>1.45 ;(2)-(3)=6.6>1.39$.

(3) $-(5)=1.9>1.45 ;(3)-(4)=1.1<1.39$.

Таким образом, только для сорбентов СКО-4 и СКО-5 различия величин сорбции витамина $\mathrm{B}_{12}$ статистически не значимы.

2. Вопрос о статистической значимости различий между величинами сорбции лучшего сорбента из коры осины и образца сравнения.

\section{1. Сорбиия метиленового синего}

Наибольшее значение величины сорбции маркера наблюдается для сорбента СКО-3 (табл.). Сравним величину его сорбции со значением для образца сравнения УА-Н. Число повторений 3 , уровень значимости 0.05 , ошибка воспроизводимости 7.53 мг/г.

В качестве нулевой гипотезы примем гипотезу о равенстве сорбции метиленового синего этими образцами (Аско-з и АуА-н). Нулевая гипотеза отвергается и различие величин считается статистически значимым, если

$$
\left(\mathrm{A}_{\text {СКО-3 }}-\mathrm{A}_{\mathrm{yA-H}}\right)>\mathrm{t}_{1-\mathrm{p}} \mathrm{S}\left(1 / \mathrm{n}_{1}+1 / \mathrm{n}_{2}\right)^{1 / 2}
$$

где $\mathrm{t}_{1-\mathrm{p}}$ - квантиль распределения Стьюдента (при степени свободы 4 и уровне значимости 0.05 равен 2.78 ); $\mathrm{S}$ ошибка воспроизводимости; $\mathrm{n}_{1}$ и $\mathrm{n}_{2}$ - число повторений.

$$
\left(\mathrm{A}_{\text {СКО-3 }}-\text { АуА-Н }\right)=200.4>17.17 .
$$

Следовательно, различие величин сорбции для данных сорбентов статистически значимо.

\section{2 Сорбиия витамина $B_{12}$}

Лучший результат по сорбции этого маркера демонстрирует сорбент из коры осины СКО-1. Сравним его значение сорбции с сорбцией образца сравнения УА-Н (АСко-1 и АуА-Н). В качестве нулевой гипотезы примем гипотезу о равенстве сорбции маркера этими образцами. Для проверки гипотезы использовали неравенство (2.1). Число повторений 3 , уровень значимости 0.05 , ошибка воспроизводимости 1.2 мг/г. При этих условиях имеем:

$$
\left(\mathrm{A}_{\text {А-Н }}-\mathrm{A}_{\text {СКО-1 }}\right)=6.0>2.74 .
$$

Следовательно, различие величин сорбции витамина $\mathrm{B}_{12}$ для данных сорбентов статистически значимо.

Для этой пары сорбентов сравним величины сорбции метиленового синего:

$$
\left(\mathrm{A}_{\mathrm{CКО-1}}-\mathrm{A}_{\mathrm{УA-H}}\right)=139>17.17
$$

Таким образом, различие величин сорбции метиленового синего для данных сорбентов также статистически значимо. 